\title{
CARDOSO DE OLIVEIRA. 2018. Desvendando evidências simbólicas: compreensão e conteúdo emancipatório da antropologia. Rio de Janeiro: Editora UFRJ. 270p.
}

\section{Marcus Cardoso}

\section{(2) OpenEdition}

\section{Journals}

Edição electrónica

URL: http://journals.openedition.org/aa/4415

DOI: $10.4000 /$ aa. 4415

ISSN: 2357-738X

\section{Editora}

Programa de Pós-Graduação em Antropologia Social (UnB)

Edição impressa

Data de publição: 1 dezembro 2019

Paginação: 383-387

ISSN: 0102-4302

\section{Refêrencia eletrónica}

Marcus Cardoso, «CARDOSO DE OLIVEIRA. 2018. Desvendando evidências simbólicas: compreensão e conteúdo emancipatório da antropologia. Rio de Janeiro: Editora UFRJ. 270p. », Anuário Antropológico [Online], v.44 n.2 | 2019, posto online no dia 03 dezembro 2019, consultado o 28 abril 2021. URL: http://journals.openedition.org/aa/4415 ; DOI: https://doi.org/10.4000/aa.4415

\section{(c) $(1)$}

Anuário Antropológico is licensed under a Creative Commons Atribuição-Uso Não-Comercial-Proibição de realização de Obras Derivadas 4.0 International. 


\section{CARDOSO DE OLIVEIRA. 2018. Desvendando evidências simbólicas: compreensão e conteúdo emancipatório da antropologia. Rio de Janeiro: Editora UFRJ. 270p.}

Marcus Cardoso

Universidade Federal de Minas Gerais - Brasil

A coletânea Desvendando evidências simbólicas reúne escritos publicados por Luís Roberto Cardoso de Oliveira nas últimas três décadas. Ao longo de dez capítulos e duas resenhas, o leitor encontra artigos que tratam do lugar da dimensão simbólica na vida social e na produção etnográfica, da comparação na antropologia, da análise de conflitos e artigos que estabelecem aproximações entre a antropologia, a filosofia e a psicanálise. A despeito da eventual distância temporal entre alguns textos que compõem a coletânea, a seleção realizada pelo autor permite identificar um conjunto de preocupações que acompanham sua trajetória acadêmica. A saber, as condições para a interpretação da dimensão simbólica da vida social, a validação do conhecimento produzido na disciplina, a vocação crítica da teoria etnográfica e seu potencial emancipatório. Trata-se de questões que costuram todos os artigos do livro.

Ao discorrer, no primeiro capítulo, sobre a dimensão simbólica da vida social e seu lugar privilegiado na antropologia, Cardoso de Oliveira apresenta as bases para as reflexões subsequentes, evidenciando seu desejo de se fazer entender por profissionais de outras áreas interessados nos métodos e discussões da disciplina. $\mathrm{O}$ antropólogo estabelece um paralelo entre as dimensões material e simbólica da vida social para demonstrar que esta última se constitui em fenômeno empírico e concreto capaz de ser apreendido analiticamente. Isto permite ao autor sustentar que o potencial mais fecundo da produção antropológica reside justamente no "desvendar evidências simbólicas” e nos procedimentos assumidos para realizá-lo.

Como a dimensão simbólica da vida social é possível de ser acessada apenas por meio das concepções de mundo dos sujeitos da pesquisa, é fundamental para a disciplina utilizar-se de um conjunto de procedimentos capazes de permitir uma conexão bem-sucedida entre os horizontes histórico-culturais do pesquisador e o ponto de vista nativo (capítulos 1 e 2). Isso acende a reflexão acerca das possibilidades de fundamentação de um conhecimento produzido com essas características e das suas dimensões crítica e emancipatória.

A possibilidade de validação das interpretações etnográficas é uma questão 
central na coletânea (capítulos 2, 3, 4, 5, 6 e 10). Todavia, é no terceiro capítulo que a provocação é tratada diretamente: é possível sustentar que um conhecimento nascido de pesquisas com foco em situações empíricas concretas nas quais a dimensão existencial ocupa um papel central no seu produto final tenha pretensões de validação acadêmico-científica? Cardoso de Oliveira argumenta que sim, acionando (e isto ocorre de modo constante na obra) a comparação entre a antropologia e a filosofia (capítulos 2, 3, 4 e 10) para sustentar sua afirmação.

É importante para o antropólogo demonstrar que, apesar da identidade da antropologia profissional ser indissociável da prática de pesquisas empíricas de caráter qualitativo, ela também é marcada por um forte diálogo e influência da filosofia. O que lhe permite afirmar que a antropologia é constituída por uma dialética radical entre ciência e filosofia, na qual se conjuga a vocação para a pesquisa empírica e a reflexão crítica. Fundamento de sustentação da validade da disciplina.

A produção de conhecimento na filosofia é a referência que sustenta seu argumento, particularmente no que se refere à preocupação da disciplina com a "internalidade” em suas análises. Procedimento esse que conjuga atenção para com a coerência interna do discurso elaborado com a necessidade de qualificar essa coerência a ponto de "persuadir seus interlocutores quanto à plausibilidade dos argumentos apresentados em relação ao problema substantivo que norteia a discussão” (p. 56). Como o antropólogo procura evidenciar, ainda que formulações dessa natureza não possam reivindicar exclusividade interpretativa, quando bem realizadas, elas são capazes de demonstrar superioridade cognitiva. O que fundamenta as pretensões de validade da disciplina. Para Cardoso de Oliveira, é importante detalhar esse processo, visto que ele se assemelha ao da antropologia.

Semelhantes, mas não iguais. Na filosofia, esse processo se dá, na maioria das vezes, num contexto de compartilhamento de pressuposições culturais. Por sua vez, na antropologia, com frequência, a pesquisa ocorre em um contexto de não compartilhamento dessas pressuposições, fazendo com que a produção de uma narrativa que atenda aos requisitos de "interioridade" não sejam apenas de outra natureza como também representem um desafio maior. Isto porque, como o produto da antropologia só é inteligível à luz das representações dos sujeitos da pesquisa, torna-se fundamental para a disciplina estabelecer algum nível de intercessão com o ponto de vista nativo ao mesmo tempo em que se mostre capaz de demonstrar seu potencial elucidativo para os eventuais leitores. O que nos remete à "fusão de horizontes" e seu papel na interpretação etnográfica. 
Outro tema central da coletânea é a vocação crítica da antropologia, discussão também indissociável da comparação entre a disciplina e a filosofia (capítulos 2, 3, 4, 5, 6, 7 e 10). Por vocação crítica, entenda-se o processo resultante do contato etnográfico que provoca uma reflexão ou desestabilização das categorias, sejam elas analíticas ou não, do pesquisador ou da pesquisadora, capaz de renovar o poder explicativo da interpretação antropológica.

Cardoso de Oliveira sustenta que o esforço em direção à "fusão de horizontes" só é bem-sucedido quando capaz de colocar em perspectiva os pressupostos, as categorias e as visões de mundo dos intérpretes da pesquisa. Um processo mais relevante em sua dimensão epistemológica do que existencial. Como destaca, a necessidade de se conviver com nossos interlocutores por longos períodos obriga-nos a enfrentar o desafio de dar sentido as nossas experiências em campo. O que, por sua vez, provoca uma reflexão sobre nossos próprios pressupostos culturais e interpretativos.

A indissociabilidade entre as discussões sobre validação e vocação crítica da interpretação antropológica torna-se evidente ao longo da coletânea. Cardoso de Oliveira sustenta que o fato de as categorias de entendimento do universo do antropólogo se fazerem presentes na produção etnográfica não deslegitimam as pretensões de validação da disciplina. Ao contrário, a dimensão crítica da produção antropológica, expressa no processo em que o interpretar das visões de mundo e modos de vida dos sujeitos da pesquisa implica, necessariamente, num pensar sobre si, é o que sustenta a capacidade da disciplina de renovar o poder explicativo das teorias etnográficas.

O terceiro tema central da coletânea é o conteúdo emancipatório da interpretação antropológica. Potencialidade também relacionada à vocação crítica da disciplina. Esta questão, que aparece como pano de fundo em todo o livro, é tratada detidamente no quinto capítulo, quando a análise de Geertz sobre a situação de Regreg e sua proposta de interpretação e comparação de sensibilidades jurídicas são criticadas por Cardoso de Oliveira.

Segundo a formulação de Cardoso de Oliveira, um aspecto interessante do potencial emancipatório da antropologia é que ele opera, ou pode operar, em sentido duplo: permite a reflexão crítica acerca das condições de existência vigente e expande a compreensão da vida social. Trocando em miúdos, para Cardoso de Oliveira, por um lado a interpretação antropológica, quando bem fundamentada, é capaz de iluminar sentidos vigentes eventualmente não percebidos anteriormente, 
expandido o potencial interpretativo da teoria etnográfica. Por outro, a interpretação antropológica possui a capacidade de subsidiar contestações diante de situações compreendidas como portadoras de déficit de sentido e experimentadas como injustas pelos sujeitos das pesquisas.

É a partir dessa discussão que Cardoso de Oliveira apresenta sua proposta de análises de conflitos. Segundo ele, para que esse potencial emancipatório se concretize, é fundamental que as interpretações antropológicas sejam capazes de produzir "avaliações coerentes dos desfechos institucionalmente produzidos na administração de conflitos, à luz de suas próprias concepções de adequação ou correção normativa" (p. 11). Procedimento que permitiria ao pesquisador ou pesquisadora distinguir desfechos considerados legítimos dentro do sistema de valores em perspectiva daqueles considerados arbitrários. Desfechos que podem indicar a vigência de "tendências estruturais à reificação" (TEaRs) de normas impositivas que carecem de sentido e legitimidade entre os sujeitos da pesquisa. Interpretação que, necessariamente, deve encontrar respaldo no ponto de vista nativo. A quem cabe decidir sobre os rumos a se tomarem.

A coletânea também conta com artigos que tratam da compreensão e comparação em Weber e Dumont, das categorias de entendimento Nuer, do contato interétnico dos krahó e das aproximações entre antropologia e psicanálise. Além de ser composta por duas resenhas. Também nesses artigos é possível identificar a presença das questões desenvolvidas nesta resenha.

Encaminhando à conclusão, é importante sublinhar que, pelos assuntos discutidos e soluções oferecidas, a coletânea representa uma importante contribuição à disciplina. Entretanto, senti falta de um desenvolvimento mais profundo do debate acerca do potencial emancipatório da interpretação etnográfica no que se refere àquilo que interessa aos sujeitos das pesquisas. Como entendo, para se explorar adequadamente todos os ângulos desse potencial emancipatório é fundamental colocar em perspectiva como as pesquisas antropológicas têm sido apropriadas por grupos vulneráveis em situações identificadas por eles próprios como injustas. Também é necessário refletir sobre as implicações dessa apropriação dentro da disciplina. O que nos conduziria a uma série de outros questionamentos também fundamentais para a antropologia contemporânea.

Recebido: 04/01/2019

Aprovado: 17/01/2019

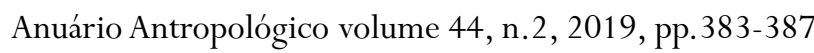


Marcus Cardoso é Doutor em Antropologia Social pela UnB. Professor do Programa de Pós-Graduação em Estudos da Fronteira da UNIFAP. Atualmente realiza estágio pós-doutoral, com financiamento da CAPES, no Programa de Pós-graduação em Ciência Política da UFMG. ORCID: https: / / orcid.org/0000-00029109-4510. Contato: marcusacardoso@gmail.com 